\title{
To What Extent Do Preschool Classrooms Match With The Architectural Design Considerations? Al-Khums City Centre, Libya as Case Study
}

\author{
Mustafa Zarigan*, Lutfi Senan , Muftah Omeman \\ Department of Architecture and Planning Engineering, College of Engineering, Elmergib \\ University, Libya \\ DOI: https://doi.org/10.21467/proceedings.4.44 \\ * Corresponding author email: mazarigan@elmergib.edu.ly
}

\begin{abstract}
In the recent few years, there has been a continued increase in the number of preschools in Libya in general and in AL-Khums city in particular. The classrooms are crucially important in terms of child development during preschool education. There is a lack of prior local studies that deal with the architectural design standards of preschools. Indeed, most preschools in Al-Khums city were not standard and appropriately designed for children as preschools. They are originally residential buildings with switched usage. The main aim of this research is to investigate to what extent the classrooms match with the principles and design standards that specific to the Libyan context in the field of preschools design. These principles and criteria for the design of preschools in $\mathrm{Al}-$ Khums city will help decision-makers, architects, educational institutions, teachers, supervisors to ensure quality education that provided to children in a perfect indoor environment. To achieve the aim of this research, three preschools in the city centre has been selected. The results let to the conclusion that all of the classrooms are not enough for indoor children's activities. Hence, it is obvious from this small-scale study that the preschools in Libya do not respond to the needs of preschoolers. Thereby, the successful architectural design of preschools is the process that meets all the functional and educational requirements. This is done by taking into account the architectural design principles for the classrooms during the design process.
\end{abstract}

Keywords: Preschools, Classrooms, Spaces, Architectural Design Principles and Considerations.

\section{Introduction}

In the recent years, the outcomes of the early education and its role in improving a child's future academic performance have been understood. However, the quality of classrooms spaces was ignored. We have a long understanding that, more than any other building type, early childhood educational facilities have a profound impact on their occupants[1]. The children are greatly influenced by the spaces and facilities of the preschools [1]. Hence, the

(C) 2018 Copyright held by the author(s). Published by AIJR Publisher in Proceedings of First Conference for Engineering

Sciences and Technology (CEST-2018), September 25-27, 2018, vol. 2 .
This is an open access article under Creative Commons Attribution-NonCommercial 4.0 International (CC BY-NC 4.0) license, which permits any non-commercial use, distribution, adaptation, and reproduction in any medium, as long as the original work is properly cited. ISBN: 978-81-936820-6-7 
To What Extent Do Preschool Classrooms Match With The Architectural Design Considerations?

design of these facilities, cannot be understated as children in this country spend more than 1000 hours in preschool in two years.

Several developed countries including Canada, USA, UK, France, Belgium and Australia had detailed guidelines for architectural design principles and considerations in terms of preschool design. Nevertheless, Libya has few architectural design considerations that are insufficient to be a guide for architects. The main scope of this research is to study indoor spaces in general and their status in classrooms in particular which appears to be more complex and raises some interesting architectural questions of significance to this research. Outdoor spaces, activities and environmental aspects are beyond this study.

There are no official statistics showing the number of children aged five and six years, but some academic sources suggest that the number of children under the age of six is up to 7 per cent $(470,000)$.

This research demonstrates how the design of the tangible indoor environment should evolve to respond to the developmental needs of preschool in terms of classrooms. Both literature and analysis on preschool environments have been used to inform architects of particular design implications used to create a physical space successful in fostering and enhancing positive child development and effective learning.

\section{Definitions}

Terminology varies from country to country. A preschool, also known as nursery school, preprimary school and kindergarten. It is an early childhood program in which children combine learning with the play before they begin compulsory education at primary school [2]. The term preschool which used in this paper is to address the educational settings visited, which are preparatory classes starting two years before primary schools. In addition, class size in this paper mentions the number of children learning in one space at one time, and how many square meters get every child.

\section{Development of Preschools in Libya}

In Libya, the first preschool - in its current form - was existed in 1910 and followed the method of Madame Montessori because the children had Italian nationality. In 1921, there were 3 preschools in Tripoli with 386 children of both sexes as well as one preschool in Benghazi and another one in Derna city. Later, in 1939, the number of preschools reached 8. After independence (1953), despite poverty and illiteracy, the Ministry of Social Security has incorporated the preschool phase into the learning system. In 1963, for the first time was referred to preschool (age 4-6 years). The following table shows the expansion of public preschools and the increase in the number of their children from 1960 to 1970[3].

ISBN: 978-81-936820-6-7 
Zarigan et al., CEST-2018, AIJR Proceedings 4, pp.770-777, 2018

Table 1: Development of preschools in Libya [3]

\begin{tabular}{|c|c|c|c|}
\hline No & Academic Year & Number of Preschools & Number of Children \\
\hline 1. & $1960-1961$ & 18 & 1830 \\
\hline 2. & $1961-1962$ & 17 & 1717 \\
\hline 3. & $1962-1963$ & 14 & 1414 \\
\hline 4. & $1963-1964$ & 21 & 1404 \\
\hline 5. & $1964-1965$ & 18 & 1697 \\
\hline 6. & $1965-1966$ & 21 & 1760 \\
\hline 7. & $1966-1967$ & 21 & 1623 \\
\hline 8. & $1967-1968$ & 24 & 1623 \\
\hline 9. & $1968-1969$ & 18 & 1418 \\
\hline 10. & $1969-1970$ & 19 & 1261 \\
\hline 11. & $1980-1981$ & 40 & - \\
\hline 12. & $1981-1982$ & 45 & - \\
\hline 13. & $1982-1983$ & 56 & 22731 \\
\hline 14. & $2006-2007$ & 341 & 49929 \\
\hline 15. & $2008-2009$ & 320 & \\
\hline
\end{tabular}

After the revolution (2011), the preschool stage became part of the educational system of the Libyan Ministry of Education. In view of the continuous encouragement and interest of the Ministry, the number of preschools increased significantly in various cities including AlKhums city. As a result, in 2015 the number of children in preschools increased by $50 \%$. For this reason, the ministry established a special management for preschools and its functions are to prepare plans, programs, organise the laws and regulations as well as develop standards, conditions, specifications for buildings and equipment for preschools, including:

1. Adherence to international standards in selecting the site in proportion to the child at this stage.

2. Adhering to international standards in the design of kindergartens buildings in conformity with international quality standards.

3. Compliance with international safety and security standards in kindergartens.

4. The beautiful and exciting entrance to the child and the beloved he has who loves him in the kindergarten.

5. Floors, columns and stairs are equipped so as to reduce the injury of the child in case of falling.

6. The existence of emergency exits in sufficient numbers and to be in children's sites, and easy to reach.

7. The presence of fire extinguishers. 
To What Extent Do Preschool Classrooms Match With The Architectural Design Considerations?

Today, preschool education is lasting two years and is for children aged four and five in order to prepare them for primary school at age of six. At the age of 4 children called the first year of foundation and 5 years of age called the second year of foundation before they go into primary school. This stage is optional. It can be publicly which funded by the education ministry or privately operated. Although, pre-schools do not have specific curricula or educational programs, the present curriculum is similar to the first year of primary school. Early years education in Libya is provided half-time for children which lasts three hours from 8:00 am to $11 \mathrm{am}$ in public preschools. Meanwhile, the private is diversity [3].

\section{$4 \quad$ Study area}

$\mathrm{Al}$ Khums (Khoms - Homs) is a city in north-western Libya. It is located on the Mediterranean coast about $120 \mathrm{Km}$ east of Tripoli, the capital of the country. It has a population of around 220,000 people. Figure 1 shows the selected preschools in the study area.

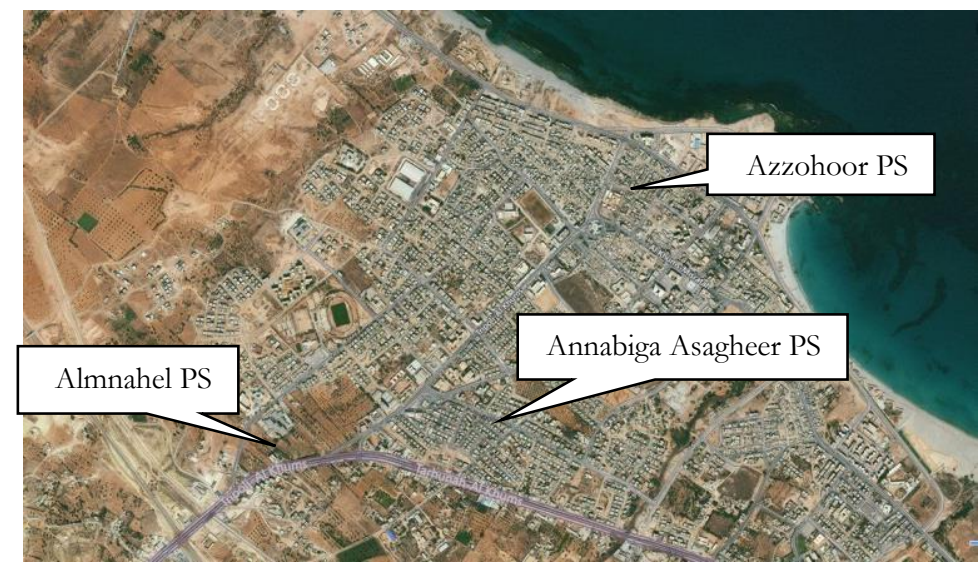

Figure 1: Alkums City- Study area

\section{$5 \quad$ Results and Discussion}

In preschool, classroom spaces are an important aspect of the learning environment for young children. The findings emphasize that not only the classrooms spaces but also the shape, furnishings and natural and artificial light and others.

\subsection{Classrooms Spaces}

Classrooms can vary in size and serve different functions, with children moving from one to another for different purposes. Instead of being single-purpose spaces, they can allow for a number of different activities, such as reading, research, group work and art. Olds (2001) stated that each child needs a space to place his/her own belongings which, in turn, give him a sense of ownership[4]. The classroom should well-equipped, with sufficient materials and toys. Planning considerations and design principles of preschools have been categorized and defined by the Libyan Urban Planning Department[5] as follows: 
- One preschool for every 4000 inhabitants and 2 preschools per primary school

- The total area of the site is 25 - 30 square meters per child

- The size of the classroom is $15-20$ children

- The walking distance from the residence to school by feet is no more than $500 \mathrm{~m}$

- Some academic The roofed area is 2.5 - 3 square meters per child

Despite the fact that preschooler needs space where he/she can play with his/her peers, smaller and quiet areas are essential for his/her own solitary activity (ergonomic) [1]. In a similar vein, classroom space should be large enough to accommodate a desired number of preschoolers. Jaclynn Shaw stated that "children are exceedingly sensitive to space; they respond to many kinds: big and small spaces, open spaces, cozy spaces, and especially hidden private spaces"[6]. Thus, the zoning of activity areas is very important. Recently, moving towards a classroom flexible in its design is a current trend within the design of preschool facilities. Therefore, designating spaces for classroom work such as reading and writing should be implemented. Besides the functional demands of the classroom, the question for design should be how the children feel inside it and how they are going to experience the space.

\subsection{Case Studies}

Three preschools has been selected (Figure 1). Two of them are basically residential buildings and the third one is designed as preschool (only one in the study area). However, its design similar to a residential building because there are no architectural design considerations have been applied in its design as preeschool. The selected case studies are:

- Azzohoor Preschool (Public Preschool)

- Almnahel Preschool (Private Preschool)

- Annabega Assageer Preschool (Private Preschool)

\section{Azzohoor Preschool (Public Preschool)}

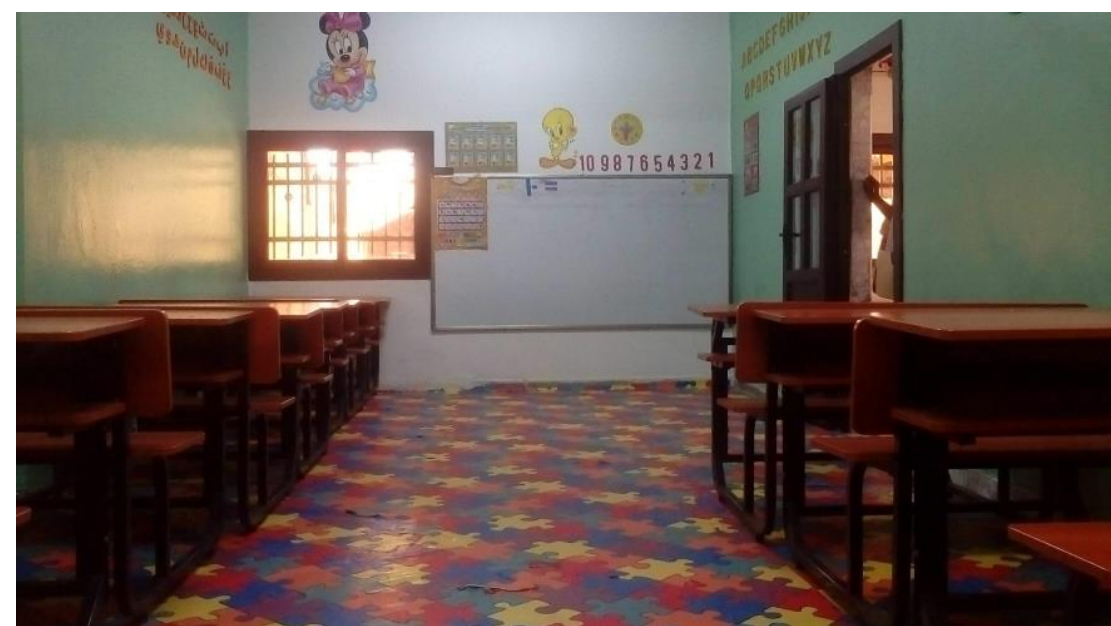

Figure 2: A classroom in Azzohoor Preschool

Proceedings of First Conference for Engineering Sciences and Technology (CEST-2018), vol. 2 774 
Table 2: Main information about Azzohoor Preschool [7]

\begin{tabular}{|c|c|c|c|c|c|c|c|c|c|}
\hline \multirow{2}{*}{ No } & \multirow{2}{*}{$\begin{array}{c}\text { No of } \\
\text { Preschoolers }\end{array}$} & \multicolumn{4}{|c|}{ Classrooms Size (m) } & \multicolumn{3}{|c|}{ No of Windows } & \multirow{2}{*}{$\begin{array}{l}\text { Size } \mathrm{m}^{2} \\
/ \text { child }\end{array}$} \\
\hline & & Area $\mathrm{m}^{2}$ & Length & width & height & units & Size $\approx \mathrm{m}^{2}$ & Direction & \\
\hline 1. & 45 & 32 & 8 & 4 & 3 & 2 & 2 & East - West & 0.71 \\
\hline 2. & 44 & 32 & 8 & 4 & 3 & 2 & 2 & West & 0.72 \\
\hline 3. & 43 & 32 & 8 & 4 & 3 & 2 & 2 & East - West & 0.74 \\
\hline 4. & 45 & 32 & 8 & 4 & 3 & 2 & 2 & East & 0.71 \\
\hline
\end{tabular}

\subsubsection{Almnahel Preschool (Private Preschool)}

Table 3: Main information about Almnahel Preschool [7]

\begin{tabular}{|c|c|c|c|c|c|c|c|c|c|}
\hline \multirow{2}{*}{ No } & \multirow{2}{*}{$\begin{array}{c}\text { No of } \\
\text { Preschoolers }\end{array}$} & \multicolumn{4}{|c|}{ Classrooms Size (m) } & \multicolumn{3}{|c|}{ No of Windows } & \multirow{2}{*}{$\begin{array}{l}\text { Size } \mathrm{m}^{2} \\
\text { / child }\end{array}$} \\
\hline & & Area $\mathrm{m}^{2}$ & Length & width & height & units & Size $\approx \mathrm{m}^{2}$ & Direction & \\
\hline 1. & 18 & 24 & 6 & 4 & 3 & 2 & 1.5 & West & 1.33 \\
\hline 2. & 18 & 18 & 4.5 & 4 & 3 & 4 & 1.6 & East & 1.00 \\
\hline 3. & 12 & 9 & 3 & 3 & 3 & 3 & 1.6 & North & 0.75 \\
\hline
\end{tabular}

\section{Annabega Assageer Preschool (Private Preschool)}

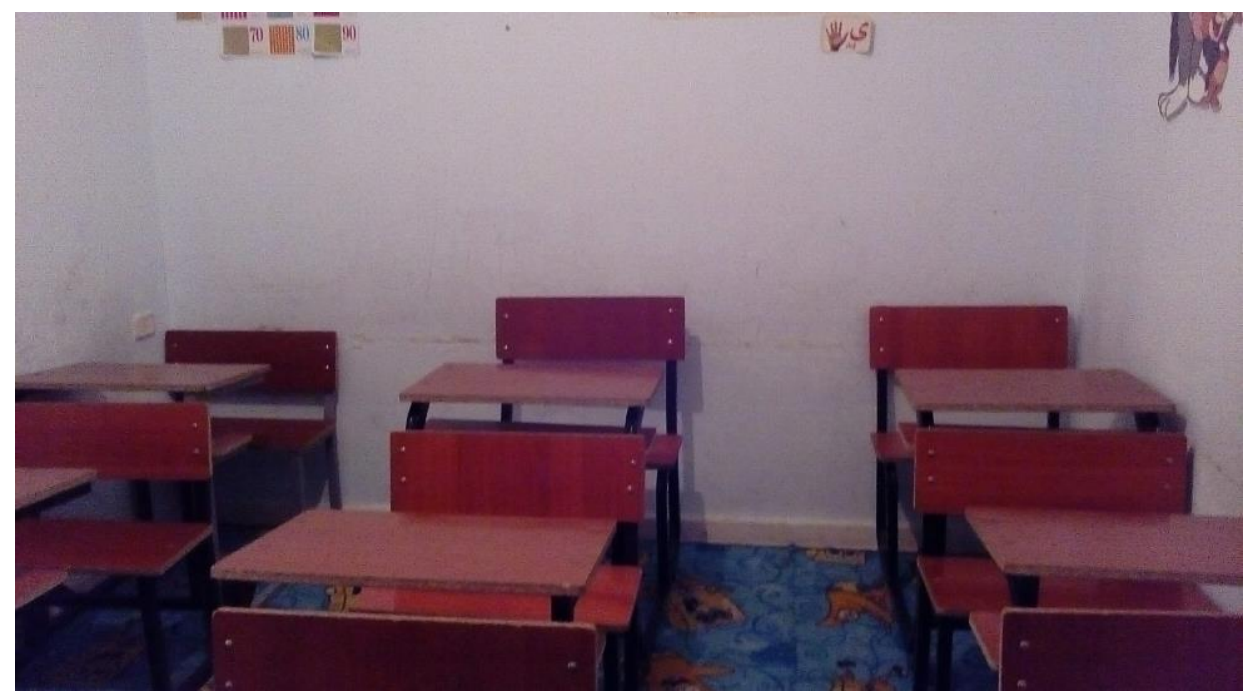

Figure 3: A classroom in Annabega Assageer 
Zarigan et al., CEST-2018, AIJR Proceedings 4, pp.770-777, 2018

Table 4: Main information about Annabega Assageer Preschool [7]

\begin{tabular}{|c|c|c|c|c|c|c|c|c|c|}
\hline \multirow{2}{*}{ No } & \multirow{2}{*}{$\begin{array}{c}\text { No of } \\
\text { Preschoolers }\end{array}$} & \multicolumn{3}{|c|}{ Classrooms Size (m) } & \multicolumn{3}{c|}{ No of Windows } & \multirow{2}{*}{$\begin{array}{c}\text { Size } \mathbf{m}^{2} \\
\text { / child }\end{array}$} \\
\cline { 3 - 11 } & & Area $\mathrm{m}^{\mathbf{2}}$ & Length & width & $\begin{array}{c}\text { heigh } \\
\mathrm{t}\end{array}$ & units & Size $\approx \mathrm{m}^{2}$ & Direction & \\
\hline $\mathbf{1 .}$ & 10 & 12.25 & 3.5 & 3.5 & 3 & 1 & 0.80 & North & $\mathbf{1 . 2 2}$ \\
\hline $\mathbf{2 .}$ & 10 & 9 & 3 & 3 & 3 & 1 & 0.80 & South & $\mathbf{1 . 1 1}$ \\
\hline 3. & 18 & 12.25 & 3.5 & 3.5 & 3 & 1 & 0.80 & North & $\mathbf{1 . 2 2}$ \\
\hline
\end{tabular}

The three preschools that were part of this research their classes are small and did not have appropriate facilities. In public preschool, for instance, space was inadequate because classrooms were overcrowded. Approximately 44 preschoolers were enrolled per classroom. The tables in three of them were arranged in lines. In addition, there are no any materials, toys, bookcases, art activities, blocks and manipulatives/fine motor. It was very poor and space generally lacked adequate lighting. Very limited attention was paid to safety issues. In the three cases, there are no bathrooms or kitchen were located near the class. Even water source not existed. In general, there is lack in numbers of toilets.

\subsection{Shape and Furnishings}

In Libya, classrooms designs are usually rectangular or square shape. For example, in one of the selected preschools, all its classrooms are rectangles $8 * 3 \mathrm{~m}$ (table 1) and some classes are only $3 * 3 \mathrm{~m}$ (as shown in tables $2 \& 3$ and figure number $3 \& 4$ ).

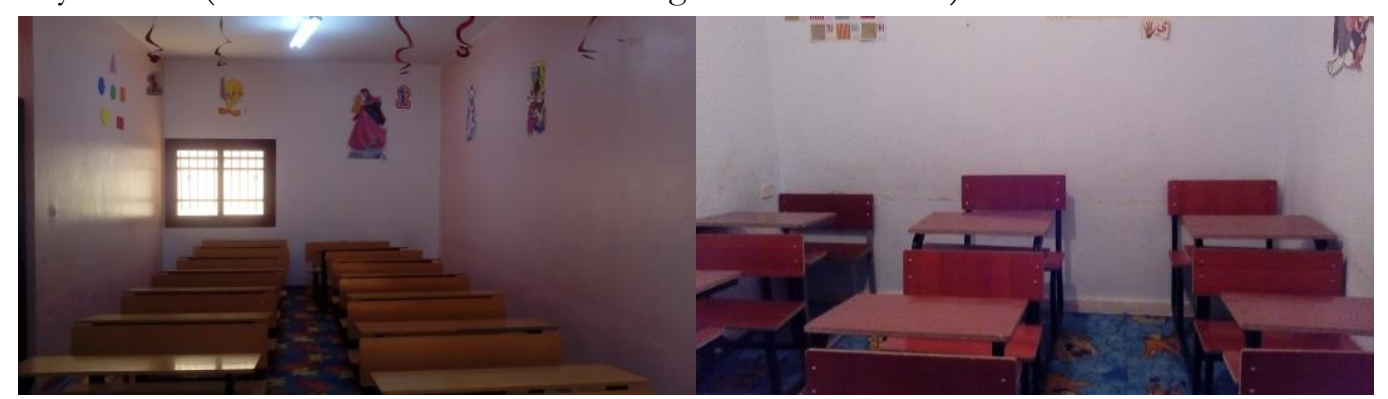

Figures 3 \& 4: classrooms are rectangular and square shape

In terms of classroom furniture, the classroom style seating is often rectangular desks that are arranged in horizontal rows which, in fact, were used in the middle of the last century. Whereas, an open classroom was implemented during the 1970s in the developed countries. This classroom type still used today [3]. Rearranging furniture in preschool classrooms may encourage classroom activities. In addition, in three examples, often only one style of furniture is used for all children. Desks and chairs in two of three preschools are the same sizes as primary schools. Moreover, the furniture characteristics are heavyweight and oversized for 
To What Extent Do Preschool Classrooms Match With The Architectural Design Considerations?

preschoolers. From previous tables, the size of the classrooms are not enough for carrying, lifting and turning desks.

\subsection{Natural and artificial Light}

There is no doubt that daylight and/or artificial light play a crucial role in the learning environment. The quality and quantity of light affect preschoolers' ability to see clearly, concentrate and learn effectively in the classroom. The light in all visited classrooms are very poor in both natural and artificial lighting (Figure5,6 \& 7). In addition, windows orientations are not applicable to the standards, for instance, some classes windows are placing in the front and in the back of the classroom which could make glare. Furthermore, their number in each classroom are very few, for example, some classrooms have only one window and its area is only $0.70 \mathrm{~m}^{2}$. Moreover, halogen and fluorescent bulbs (lamps) are only one or two in each classroom.

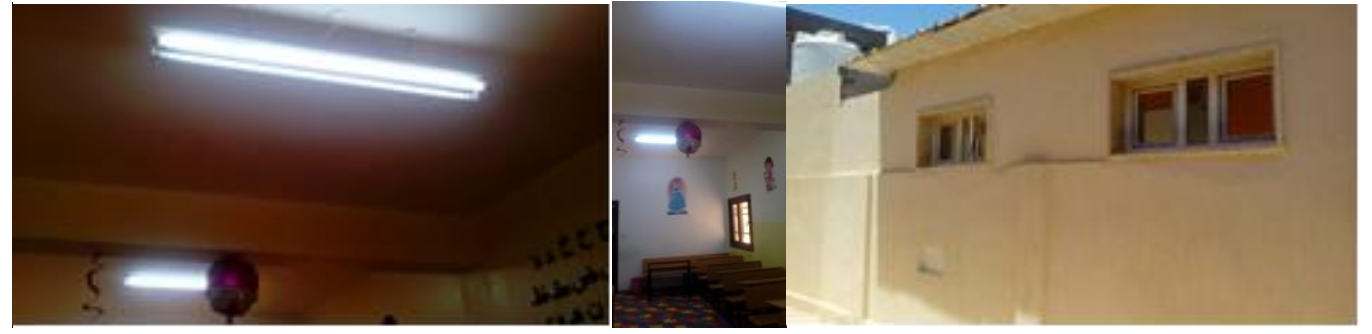

Figures 5, 6 \& 7: Natural and artificial lighting in different classrooms

\section{Conclusions}

It is notable that most preschools in the study area are not standard and appropriately designed for children. They are mostly located in residential areas and apartment buildings that are painted to suit children. Recently, the Ministry of Education has focused on the educational progress of children in preschools. We hope that running the functional ideas of this study and considering the conditions, climate, and environment lead to a guideline for designing a standard preschool where children can learn, play, and grow up. This research can be generalized to other educational spaces such as elementary schools, training centres, and centres for Intellectual Development of Children and Adolescents. More studies in larger research fields are recommended for designing preschools environment, with a focus on indoor and outdoor elements, to improve children's learning.

\section{References}

[1] Day, D. E. (1983). Early childhood education: A human ecological approach (T.W. Hipple, Ed.). Glenview, Illinois: Scott, Foresman and Company

[2] B. E Şahin \& N. Dostoğlu, "Evaluation of Kindergarten Group Rooms in the Context of Size: Children and Teacher's Perspective in Turkey. European Journal of Contemporary Education, 2014, Vol.(10), № 4

[3] Amer, F. O (2018). Education in Libya and some other countries: A comparative study Access online on 19 August 2018 at www.bing.com

[4] Olds, 2001, The Libyan Urban Planning Department

[5] Jaclynn, S, The Ministry of Education. Preschool management, Alkhums branch. 